\title{
LA HIPOCRESÍA EMPRESARIAL ${ }^{1}$
}

CORPORATE HYPOCRISY

\section{Manuel Alfonso Garzón Castrillón}

Grupo de Investigación FIDEE

Fundación para la Investigación y el Desarrollo Educativo Empresarial

Barranquilla, Colombia, Sur América

manuelalfonsogarzon@fidee.org

Fecha de recepción: 23/03/2021 - Fecha de aprobación: 07/05/2021

DOI: https://doi.org/10.36995/j.visiondefuturo.2021.26.01.005.es

\section{RESUMEN}

Este artículo de revisión tuvo como objetivo aportar a la comprensión de la importancia de la coherencia entre el decir y el actuar para evitar que las empresas sean percibidas desde la perspectiva de la hipocresía empresarial y afecten la marca, la reputación, la confianza y la credibilidad en la empresa. Se realizó con base en el Methodi Ordinatio abordando sus orígenes teóricos para luego acercarse al concepto, posteriormente incursionar en los diferentes estudios que se han aproximado a éste desde la responsabilidad social empresarial (RSE), la ética; la reputación, los grupos de interés (stakeholders), y la comunicación, posteriormente en relación a las consecuencias que genera en organizaciones conocidas mundialmente, sus declaraciones y la crítica realizada, posteriormente se hace un análisis de tres aspectos o facetas en las cuales se presenta a saber :la hipocresía moral; la hipocresía conductual y como atribuir la hipocresía empresarial, en el siguiente punto se presenta una tipología que involucra dos dimensiones: una orientación que hace referencia a la capacidad de atención, a corto y largo plazo de participantes al hacer o responder a acusaciones de hipocresía y una dirección temporal, la cual se refiere al punto de comparación, pasado o futuro, finalmente se llega a unas conclusiones, y unas implicaciones prácticas.

PALABRAS CLAVES: Hipocresía empresarial; ética empresarial; comunicación empresarial, RSE.

\section{ABSTRACT}

This review article aimed to contribute to the understanding of the importance of coherence between saying and acting to prevent companies from being perceived from the perspective of

${ }^{1}$ Proyecto de ética empresarial, Código: INV-5539-2020.

"Visión de Futuro" Año 19, Volumen $\mathbf{N}^{0} 26 \mathbf{N}^{0}$ 1, Enero - Junio 2022 - Pág 169 - 189

URL de la Revista: http://visiondefuturo.fce.unam.edu.ar/index.php/visiondefuturo/index

URL del Documento: https://visiondefuturo.fce.unam.edu.ar/index.php/visiondefuturo/issue/view/22

ISSN 1668 - 8708 - Versión en Línea

E-mail: $\underline{\text { revistacientifica@fce.unam.edu.ar }}$ 
business hypocrisy and affecting the brand, reputation, trust and credibility in the company. It was carried out based on the Methodi Ordinatio, addressing its theoretical origins and then approaching the concept, later venturing into the different studies that have approached it from corporate social responsibility (CSR), ethics; reputation, interest groups (stakeholders), and communication, subsequently in relation to the consequences that it generates in world-known organizations, their statements and the criticism made, subsequently an analysis of three aspects or facets is made in which it is presented namely: moral hypocrisy; behavioral hypocrisy and how to attribute business hypocrisy, the next point presents a typology that involves two dimensions: an orientation that refers to the attention span, in the short and long term of participants when making or responding to accusations of hypocrisy and a temporal direction, which refers to the point of comparison, past or future, finally reaches some conclusions, and some practical implications.

KEY WORDS: Business hypocrisy; Business ethics; Business Communication, CSR.

\section{INTRODUCCIÓN}

Aunque la hipocresía empresarial puede parecer un concepto sencillo a primera vista, el examen más elemental revela que nuestra comprensión es todavía limitada, la hipocresía es una acusación muy compleja para las empresas al desafiar su integridad moral, y puede surgir de los grupos de interés ante la sospecha de estar infringiendo su propio discurso con sus acciones, pero esta forma de concebir la hipocresía empresarial, han pasado a entenderla incluso cuando no hay una expresión abierta por parte de la empresa.

De esta manera la hipocresía empresarial es un área de investigación emergente debido a un aumento en el número de empresas que son percibidas como hipócritas por afirmar ser algo que no lo son como lo afirma Goswami y Ha-Brookshire (2016)

La hipocresía empresarial influye en el grado en que los grupos de interés confían en otros, por tanto, afirmaciones falsas e inexactas, el etiquetado incorrecto, las promociones falsas e inexactas, la publicidad engañosa, las promociones falsas, el marketing para atraer a los clientes con un precio muy bajo y después persuadirlos para que compran un producto similar a un precio mayor, argumentando la terminación de existencias (Bait marketing), la obsolescencia planeada, los productos falsificados, infringir los derechos de autor, realizar prácticas inmorales de líderes deshonestos para aprovecharse de los grupos de interés se presentan en todas las industrias sin excepción.

\footnotetext{
"Visión de Futuro" Año 19, Volumen $N^{\circ} 26$ Nº 1, Enero - Junio 2022 - Pág 169 - 189

URL de la Revista: http://visiondefuturo.fce.unam.edu.ar/index.php/visiondefuturo/index

URL del Documento: https://visiondefuturo.fce.unam.edu.ar/index.php/visiondefuturo/issue/view/22

ISSN 1668 - 8708 - Versión en Línea

E-mail: $\underline{\text { revistacientifica@fce.unam.edu.ar }}$
} 
Las implicaciones de la hipocresía empresarial a nivel de los colaboradores permanecen sin explorar, para Carlos y Lewis, (2018) en lo relacionado con los efectos directos e indirectos, para quienes sus trabajos son de mayor importancia para la tarea, y corren el riesgo de ser percibidos como hipócritas cuando tales compromisos no se cumplen.

Las crecientes demandas de los grupos de interés pueden empujar a las organizaciones a retrasarse en el cumplimiento de las expectativas sociales y morales generadas y se exponen a ser percibidos como hipócritas, al no cumplirlos, de esta manera la hipocresía puede surgir cuando una organización envía un mensaje de valoración de sus empleados y luego ofrecen malas condiciones de trabajo. Las investigaciones realizadas por Shim y Yang, (2016), muestran que la hipocresía empresarial es especialmente destacada y provoca fuertes reacciones negativas cuando los grupos de interés observan una falta de alineación entre palabras y hechos de las organizaciones, como afirmaciones sin fundamento de la calidad del producto o servicio, la salud de los colaboradores, su seguridad y la protección del medio ambiente entre otras.

En consecuencia, este documento tiene como objetivo aportar al enfoque de la literatura actual sobre hipocresía empresarial al abordar los orígenes teóricos del concepto de hipocresía empresarial, para luego acercarse al concepto de hipocresía empresarial hasta el año 2020, para posteriormente incursionar en los diferentes estudios que se han aproximado a la hipocresía empresarial desde la responsabilidad social empresarial (RSE), la ética; la reputación, los grupos de interés (stakeholders), y la comunicación, posteriormente se realiza un revisión de las consecuencias de la hipocresía empresarial en organizaciones conocidas mundialmente, sus declaraciones y la crítica realizada por hipocresía empresarial, posteriormente se hace un análisis de los aspectos de la hipocresía empresarial para proponer tres aspectos o facetas en las cuales se presenta: la hipocresía moral; la hipocresía conductual y como atribuir la hipocresía empresarial, en el siguiente punto se presenta una tipología que involucra dos dimensiones: una orientación que hace referencia a la capacidad de atención, a corto y largo plazo de participantes al hacer o responder a acusaciones de hipocresía y una dirección temporales, donde la dirección temporal se refiere al punto de comparación, pasado o futuro, finalmente se llega a unas conclusiones, y unas implicaciones prácticas.

\section{Método}

En la presente investigación, se utilizó el Methodi Ordinatio de Pagani; Kovaleski; y Resende, (2015);con base en la cual se desarrollaron las etapas propuestas por los autores que incluyen Fase 1: Establecer la intención de la investigación; Fase 2: investigación preliminar

\footnotetext{
“Visión de Futuro" Año 19, Volumen No 26 N 1, Enero - Junio 2022 - Pág 169 - 189

URL de la Revista: http://visiondefuturo.fce.unam.edu.ar/index.php/visiondefuturo/index

URL del Documento: https://visiondefuturo.fce.unam.edu.ar/index.php/visiondefuturo/issue/view/22

ISSN 1668 - 8708 - Versión en Línea

E-mail: revistacientifica@fce.unam.edu.ar
} 
exploratoria con palabras clave en bases de datos, la combinación de palabras clave y sus posibles combinaciones; Fase 3: definición y combinación de palabras clave y bases de datos, las utilizadas fueron: business hypocrisy; business ethics; business communication, csr, stakeholders- hypocrisy, marketing -hipocresy, reputation and corporate hypocrisy; communication and business hypocrisy; Fase 4: Búsqueda final en las bases de datos, las bases de datos consultadas Scopus, WoS, y Scielo; Fase 5: procedimientos de filtrado, para eliminar trabajos repetidos o documentos que no pertenecen al área de investigación de interés, analizando el título, las palabras clave y el resumen; Fase 6: identificación del factor de impacto, año de publicación y número de citas; Fase 7:Clasificación de los trabajos utilizando InOrdinatio

La clasificación de los trabajos utilizando la formula del InOrdinatio de Paganiet.al. (2015); InOrditnatio=(IF/1000) $\alpha^{*}[10-($ Año de investigación -año de publicación)]+( $\Sigma \mathrm{Ci})$, donde: (Pagani et.al (2015)

- IF es el factor de impacto, a es un factor de ponderación que va de 1 a 10, que debe ser atribuido por el investigador;

- ResearchYear es el año en el que se desarrolló la investigación;

- $\quad$ PublishYear es el año en que se publicó el artículo; y

- $\quad$ Sumatorio $\mathrm{Ci}(\Sigma \mathrm{Ci})$ es la cantidad de veces que se citó el artículo.

La Fase 8 fue la búsqueda de los documentos completos, con base en los resultados obtenidos y la clasificación de los artículos, se pasó a la consecución de los cuarenta y cinco (45) documentos completos resultado del tamizaje realizado; Fase 9: Lectura final y análisis sistemático de los trabajos buscando aquellos aspectos considerados relevantes para el artículo, tales como autores principales, variables identificadas, definiciones, enfoques, taxonomías, resultados logrados, modelos propuestos, comparaciones, vacíos de investigación, para posteriormente pasar a la organización de los datos; el análisis de contenido y la redacción.

\section{Antecedentes}

Los orígenes teóricos del concepto de hipocresía se encuentran en los tiempos iniciales de la literatura sobre filosofía y psicología, desde la Psicología Norden, (1957) afirma que la hipocresía cubre una variedad de fenómenos, siendo un método de adaptación del ego abordando la hipocresía como algo que ocurre a nivel personal, por su parte Dickey (1990) quien en sus análisis usa la idea de hipocresía para llamar la atención sobre el desdén, sobre la brecha entre apariencia y realidad del comportamiento humano en Francia del siglo XVIII, país en el cual la hipocresía social fue una estrategia para evitar el estigma de la vergüenza que orientaba las

\footnotetext{
"Visión de Futuro" Año 19, Volumen $N^{\circ} 26$ Nº 1, Enero - Junio 2022 - Pág 169 - 189

URL de la Revista: http://visiondefuturo.fce.unam.edu.ar/index.php/visiondefuturo/index

URL del Documento: https://visiondefuturo.fce.unam.edu.ar/index.php/visiondefuturo/issue/view/22

ISSN 1668 - 8708 - Versión en Línea

E-mail: revistacientifica@fce.unam.edu.ar
} 
acciones de los comerciantes de la época, y desde lo personal Tedeschi, Sclenker y Bonoma,(1971) afirman que un individuo es considerado hipócrita cuando existe un conflicto entre lo que dice y lo que hace y revisando el origen etimológico se encontró que proviene del latín hypocrisis y del griego hipokrisis y su significado hace referencia a los vocablos actuar o fingir, que significa máscara y respuesta para representar un personaje, finalmente y en lo relacionado con las empresas, que las palabras y los hechos de los gerentes y miembros generales de la organización son diferentes. Argyris y Schon, (1974).

Las primeras investigaciones realizadas por Kerr (1975) concluyen que los sistemas de recompensas organizacional fomentan comportamientos contradictorios con los de la empresa, y los valores declarados pueden aumentar las percepciones de hipocresía de los grupos de interés.

La hipocresía para Szabados, (1979) desde la filosofía, es un término de condena moral, de hecho, a menudo uno muy fuerte e inteligible, por tanto, la hipocresía es un asunto de interés propio: el hipócrita se propone promover su ventaja a expensas de los demás, por tanto, los casos de hipocresía no son casos de autoengaño. Por su parte Shklar, (1984) afirma que la hipocresía se ha caracterizado como un pecado imperdonable, porque cuando las organizaciones asumen una falsa apariencia o no están a la altura de sus ideales, violan normas sociales profundamente arraigadas de honestidad e integridad y la percepción de hipocresía tiende a manifestarse cuando ocurre una distancia entre las afirmaciones y la actuación, porque según Brunsson (1989) la hipocresía es una estrategia potencial para responder a diversas demandas del mercado a menudo inconsistentes con su filosofía empresarial.

De lo anterior se puede inferir que la hipocresía se ha estudiado desde tiempos inmemoriales como el siglo XVIII y los años cincuenta, del siglo XX, desde diferentes enfoques como la psicología, la filosofía, relacionada con el comportamiento personal y desde la década de los setenta en lo relacionado con las empresas y los grupos de interés.

\section{El concepto de hipocresía empresarial}

En esta sección revisaremos las definiciones más desatacadas sobre hipocresía empresarial y se puede inferir que coinciden en abordar la hipocresía desde una dimensión moral y ética Christensen,et.al. (2020).

Desde el comportamiento inapropiado, o con discrepancias en las prácticas como generadora de comportamientos diferentes o comportamiento del pasado loannou, et.al (2018); Etter et.al. (2019);

\footnotetext{
"Visión de Futuro" Año 19, Volumen $N^{\circ} 26$ Nº 1, Enero - Junio 2022 - Pág 169 - 189

URL de la Revista: http://visiondefuturo.fce.unam.edu.ar/index.php/visiondefuturo/index

URL del Documento: https://visiondefuturo.fce.unam.edu.ar/index.php/visiondefuturo/issue/view/22

ISSN 1668 - 8708 - Versión en Línea

E-mail: $\underline{\text { revistacientifica@fce.unam.edu.ar }}$
} 
Relacionado con una inconsistencia o brecha en sus compromisos, porque en realidad no practica lo que predica, afirma ser algo que no es, no coincide con las promesas, es de forma simbólica, o hay disparidad entre palabras y hechos; Leonidou y Skarmeas, (2017); Scheidler, et.al., (2018) Zhao et.al (2020).

Como una percepción o juicio externos de los grupos de interés, Carlos y Lewis, (2018)

Porque socava las actitudes positivas de los consumidores, hacia la marca o la empresa Sweetin, et.al., (2013).

En general, la literatura consultada sobre hipocresía revela un fenómeno generalizado en todos los contextos y dominios, que refleja facetas morales, que pueden convertirse en rasgos de carácter atribuidos a una empresa y nos permite deducir que la hipocresía no solo es inestable, sino que juega un papel mucho más complejo en la configuración de las organizaciones contemporáneas.

De la revisión realizada después de efectuar un proceso de integración, fusión y unión, con base en los aspectos más destacados y en los que la mayoría de los autores están de acuerdo se llega a la propuesta de esta definición de hipocresía empresarial: Desde una dimensión moral y ética, se refleja en un comportamiento inapropiado o con discrepancias, inconsistencias 0 brecha en sus compromisos, porque en realidad no practica lo que predica, afirma ser algo que no es, no coincide con las promesas, es de forma simbólica, o hay disparidad entre palabras y hechos, generando una percepción o juicio externo de los grupos de interés, que socava las actitudes positivas de los consumidores, hacia la marca y/o la empresa.

\section{Estudios sobre hipocresía empresarial}

\section{La RSE y la hipocresía empresarial}

La literatura explora la hipocresía desde diferentes ángulos, Shim y Yang (2016) concluyen que la RSE no es una varita mágica para impulsar la reputación de una empresa, y si motivos altruistas apreciados por los grupos de interés, promoviendo una campaña relacionada con problemas o crisis coyunturales para mitigar una publicidad negativa o una crítica a sus operaciones comerciales poco éticas.

La investigación realizada por Scheidler, Edinger-Schos, Spanjol y Wieseke (2018) analiza las percepciones y respuestas de los empleados hacia estrategia hipócritas de RSE de sus empleadores, Hafenbrädl y Waeger (2019) concluye que enmarcar la RSE en términos de caos de negocios es una de las principales estrategias cuando el objetivo de la empresa es gestionar las impresiones de los grupos de interés, y cuando pueden surgir informaciones o especulaciones

\footnotetext{
"Visión de Futuro" Año 19, Volumen N²6 N 1, Enero - Junio 2022 - Pág 169 - 189

URL de la Revista: http://visiondefuturo.fce.unam.edu.ar/index.php/visiondefuturo/index

URL del Documento: https://visiondefuturo.fce.unam.edu.ar/index.php/visiondefuturo/issue/view/22

ISSN 1668 - 8708 - Versión en Línea

E-mail: revistacientifica@fce.unam.edu.ar
} 
que desafíen el compromiso de la empresa, Andersen y Høvrin (2019) contribuyen examinado empíricamente las consideraciones de los grupos de interés como representaciones de historias para mostrar, como diálogos que fomentan nuevas manifestaciones de hipocresía y que centrarnos en el presente nos obliga a redirigir nuestro enfoque analítico hacia las discrepancias relacionadas con el tiempo.

Los resultados de la investigación realizada por Losada-Otálora y Alkire (2019) sugieren que las actividades relacionadas con la RSE, como compartir información de productos con los clientes, muestra que a una mayor transparencia de la información se pueden reducir los riesgos de que las empresas sean juzgadas como hipócritas, por el contrario, la falta de transparencia desencadena la acusación de hipocresía.

Sobre los estudios en los que se relaciona la hipocresía con la RSE, Wagner, Korschunb y Troebsa (2019) establecen que, a pesar de los claros avances en la investigación sobre hipocresía empresarial, la investigación hasta ahora ha sido limitada principalmente en RSE, porque es quizás el área en la cual es más común que la empresa diga una cosa y haga otra.

Los resultados obtenidos por Zhao Y, Qin Y, Zhao X, Wang X and Shi L (2020) muestran que las comunicación de RSE afecta positivamente la implementación de ésta, esto implica que aunque los consumidores perciban la hipocresía empresarial basada en la comunicación y la implementación de RSE, su percepción está determinada en última instancia por la percepción de las motivaciones de las empresas convirtiéndose en el factor crucial para establecer la percepción de hipocresía empresarial, por tanto, si los consumidores perciben una motivación impulsada por el valor social o medio ambiental detrás de la comunicación e implementación de la RSE de la empresas, éstos asumirán que la empresa es sincera y la disparidad entre palabras y hechos será modesta, desarrollando un menor nivel de hipocresía empresarial, pero si percibe una motivación impulsada por el desempeño, los grupos de interés sospecharán y generarán una mayor percepción de hipocresía empresarial.

\section{La ética y la hipocresía empresarial}

En relación con la ética y la hipocresía empresarial, establecen Shim y Yang (2016) la hipocresía empresarial se refiere a un juicio ético de los consumidores sobre los esfuerzos prosociales y filantrópicos de una organización y en relación con la creencia de que una empresa afirma ser algo que no es. Por tanto, según Isserow y Klein (2018); y Effron, O'Connor, Leroy y Lucas. (2018) la investigación sobre hipocresía empresarial sugiere que las deviaciones intencionales de las declaraciones pueden ser peores que las involuntarias porque revelan fallas

\footnotetext{
“Visión de Futuro" Año 19, Volumen No 26 N 1, Enero - Junio 2022 - Pág 169 - 189

URL de la Revista: http://visiondefuturo.fce.unam.edu.ar/index.php/visiondefuturo/index

URL del Documento: https://visiondefuturo.fce.unam.edu.ar/index.php/visiondefuturo/issue/view/22

ISSN 1668 - 8708 - Versión en Línea

E-mail: revistacientifica@fce.unam.edu.ar
} 
morales, aunque la investigación sobre hipocresía empresarial no ha distinguido entre actos intencionales y no intencionales, lo anterior es necesario porque si la hipocresía difiere a nivel personal dependiendo de la intencionalidad en las organizaciones también se deben distinguir.

\section{Reputación e hipocresía empresarial}

En lo pertinente a la relación entre reputación e hipocresía empresarial Effron, Lucas y O'connor (2015) concluyen que los riesgos de la hipocresía percibida por los grupos de interés dependen en gran medida del grado en que la organización experimente una amenaza a la reputación en el mismo ámbito que la afirmación implícita de una certificación, si esto se presenta, la reputación se ve afectada por presentarse una contradicción directa entre las afirmaciones y las acciones, y si es de forma contraria, la percepción es de coherencia, que en relación con empresas de alto prestigio y reputación como Microsoft, para Carroll (2016) le han permitido el recaudo de más de mil millones de dólares en contribuciones para más de 31.000 organizaciones.

Los resultados de la investigación realizada por Donia y Sirsly (2016) muestran que algunas acciones de RSE se consideran genuinas mientras que otras falsas, y esta hipocresía según Arli, Grace, Palmer, y Pham (2017) influye tanto en las creencias y actitudes de los consumidores hacia la organización y para Adams,(2015) las actividades que parecen genuinas aumentan el nivel de confianza que siente un consumidor, lo que significa que a niveles bajos de hipocresía percibida , mayor reputación de la empresa o de marca.

Desde la perspectiva de los grupos de interés los hallazgos de Siano, Vollero, Conte y Amabile, (2017) establecen que no todas las declaraciones de los CEO deben tomarse al pie de la letra, desafortunadamente la irresponsabilidad empresarial es frecuente, ya que las organizaciones parecen ser socialmente responsables desde una perspectiva externa, pero internamente mantienen estándares, sistemas y procesos que, muestran una manipulación engañosa.

Los resultados a los que llegan Hafenbrädl y Waeger, (2019) confirman que las organizaciones deben tener un marco moral fuerte y que cuando no lo es, conduce a evaluaciones morales desfavorables de los directores o ejecutivos y a sus empresas y diferentes a las que se observan cuando el marco moral fuerte está presente en pensamiento y acción.

\section{Stakeholders e hipocresía empresarial}

En la relación entre stakeholders e hipocresía empresarial, la hipocresía provoca según Greenbaum, Mawritz, y Piccolo, (2015) agotamiento emocional y aumenta las intenciones de

\footnotetext{
“Visión de Futuro" Año 19, Volumen No 26 N 1, Enero - Junio 2022 - Pág 169 - 189

URL de la Revista: http://visiondefuturo.fce.unam.edu.ar/index.php/visiondefuturo/index

URL del Documento: https://visiondefuturo.fce.unam.edu.ar/index.php/visiondefuturo/issue/view/22

ISSN 1668 - 8708 - Versión en Línea

E-mail: revistacientifica@fce.unam.edu.ar
} 
rotación de los colaboradores y para Arli, et.al (2017) la hipocresía puede afectar negativamente las evaluaciones que realizan los grupos de interés en términos de RSE, actitudes hacia la organización y la reputación, para Bakker y den Hond (2017) no es sólo la empresa la que actúa hipócritamente, sino todos los participantes del diálogo entre stakeholders internos y externos de la empresa, de esta manera el diálogo con los grupos de interés no debe ser por defecto, sino que debe ser un medio para evitar resolver acusaciones de hipocresía y reducen para Guèvremont y Grohman (2018) la disposición de los consumidores a pagar por un producto, por tanto, la hipocresía es fundamental para entender y comprender a los diferentes grupos de interés.

Para loannau et.al. (2018), los grupos de interés son claves para percibir la hipocresía, independientemente de las intenciones corporativas, y puede tener implicaciones tangibles negativas incluso exageradas dependiendo de las características idiosincráticas de la región y su relación con las empresas, buscando evitar tomar acciones que pueden ser percibidas como hipócritas, para lo cual es importante poner en marcha una estrategia de participación y diálogo permanente con los grupos de interés, evitando debilitar significativamente la capacidad de una empresa para construir con ellos, sentido de conexión con la empresa.

Para Andersen y Høvrin (2019) es fundamental para la organización comprender la afiliación de los diferentes grupos de interés a fin de evitar comportamientos de hipocresía y uno de los grupos de interés que para Scheidler, Edinger-Schons, Spanjol y Wieseke (2019) ha guardado silencio son los internos (los colaboradores) y que para Wagner et.al (2019) un liderazgo hipócrita de la gerencia puede hacer que los colaboradores tengan respuestas conductuales negativas.

\section{Comunicación e hipocresía empresarial}

Sobre la relación de la comunicación en la hipocresía empresarial, Shim y Yan (2016) encontraron que uno de sus hallazgos radica en el efecto mediático de la percepción de hipocresía en la formación de actitudes hacia la empresa en general, por tanto, es importante considerar que la autenticidad, la honestidad y la sinceridad en la estrategia de comunicación debe contener dos aspectos el de rentabilidad y el de moralidad.

Para Babu, De Roeck y Raineri, (2019) la hipocresía empresarial afecta negativamente la percepción de los empleados cuando los gerentes están comunicando acciones organizacionales futuras a sus empleados, por tanto, necesitan cumplir lo que afirman que harán y deben ser transparentes en sus políticas y procedimientos, evitando divulgar sus logros positivos para evitar

\footnotetext{
"Visión de Futuro" Año 19, Volumen No 26 N 1, Enero - Junio 2022 - Pág 169 - 189

URL de la Revista: http://visiondefuturo.fce.unam.edu.ar/index.php/visiondefuturo/index

URL del Documento: https://visiondefuturo.fce.unam.edu.ar/index.php/visiondefuturo/issue/view/22

ISSN 1668 - 8708 - Versión en Línea

E-mail: $\underline{\text { revistacientifica@fce.unam.edu.ar }}$
} 
un escrutinio más profundo que a menudo dan como resultado reclamos de autopromoción excesivos.

Finalmente, en estos estudios sobre hipocresía empresarial, Andersen y Høvrin (2019) concluyen que hablar de hipocresía implica una relación más compleja entre hablar y actuar, que excede la correspondencia simple y la causalidad lineal; que es fundamental para la afiliación organizacional y proporciona una comprensión más profunda de quien está actuando hipócritamente; que es omnipresente e ineludible en las organizaciones; es una construcción compleja, es una cuestión de percepción y creación de sentido impulsada por la autorreflexión de los actores.

\section{Las consecuencias de la hipocresía empresarial}

La hipocresía empresarial influye en el grado en que los individuos confían en otros, y el grado en que se vuelven cínicos acerca de su organización, por tanto, para aquellas empresas que no reconocen la importancia de los valores proclamados y las expectativas generadas, pueden traer consecuencias patológicas para la organización. Kowal y Roztocki (2015)

Se pueden clasificar en dos categorías, las consecuencias de la hipocresía individuales y organizacionales, según Kılıçoglu, Kılıçoglu y Hammersley-Fletcher (2019), quienes concluyen en su estudio, que las consecuencias individuales son nefastas desde lo individual, pérdida de confianza, entre los colaboradores y los directivos, impacto negativo en la motivación y la satisfacción laboral y el compromiso con la organización, llegan a afirmar los colaboradores que se sentían inútiles, infelices, enojados, indignados e inquietos, generando mala comunicación con sus directivas.

Por su parte Goswami, (2017) afirma que las prácticas poco éticas como promociones falsas, marketing de señuelo, publicidad falsa o reclamos inexactos, productos falsificados, etiquetado incorrecto e infracción de la privacidad para el marketing son comunes en diferentes industrias y como respuesta concluye Zhigang, Lei, y Xintao,; (2020) que los consumidores muestran comportamientos emocionales fuertes, porque se sienten engañados por la empresa, esas respuestas son diferentes dependiendo del contexto, y juegan un papel importante en la formación de percepciones de hipocresía de los consumidores y las emociones negativas juegan un papel crucial en las actitudes y repuesta de comportamiento de éstos, por tanto una alta expectativa y una baja percepción de desempeño de la empresa, conducen a una alta percepción de hipocresía entre los consumidores y efectos negativos hacia la empresa.

\footnotetext{
"Visión de Futuro" Año 19, Volumen No 26 Nº 1, Enero - Junio 2022 - Pág 169 - 189

URL de la Revista: http://visiondefuturo.fce.unam.edu.ar/index.php/visiondefuturo/index

URL del Documento: https://visiondefuturo.fce.unam.edu.ar/index.php/visiondefuturo/issue/view/22

ISSN 1668 - 8708 - Versión en Línea

E-mail: revistacientifica@fce.unam.edu.ar
} 
Los estudios de Arli; van Esch; Northey; Lee; y Dimitriu;(2019)., confirman el efecto negativo y el escepticismo que generan en los grupos de interés, pero un hallazgo importante radica en que, si los grupos de interés tienen expectativas bajas de cierta industria como la cerveza y el tabaco e irónicamente si las empresas tienen comportamientos prosociales, y generan expectativas altas, tiene más que perder cuando los grupos de interés las perciben hipócritas.

Los resultados obtenidos por loannou et.al. (2018) sugieren que la hipocresía percibida tiene un efecto fuertemente negativo en la satisfacción del cliente, pero solo para empresas que hacen seguimiento y monitoreo permanente a éstos, es como echarle sal a la herida y empeoran los juicios o percepciones negativas de los clientes.

En el trabajo de investigación de Manikab, y Athanasopouloua (2018) concluyen que una organización no solo debe coordinar estratégicamente las diferentes herramientas de comunicación para brindar claridad y coherencia en sus mensajes, sino que debe evitar la autopromoción, porque paradójicamente si comunica demasiado puede generar expectativas que logran dañar su credibilidad.

Con relación a los colaboradores, Yanga et.al. (2018) concluye que las organizaciones deben hacer un esfuerzo para comunicar de una manera clara para que ellos vean que su participación es importante, en particular para eliminar comportamientos hipócritas, las organizaciones pueden hacer que los empleados sean responsables mediante la formalización de programas auténticos y establecer metas financieras o sociales para el desempeño.

A continuación, se relacionan siete (7) empresas conocidas mundialmente, las declaraciones realizadas y las críticas generadas por hipocresía:

Tabla 1. Empresas declaraciones y críticas por hipocresía empresarial

\begin{tabular}{|c|c|c|c|}
\hline No & Empresa & Declaración & Critica por hipocresía empresarial \\
\hline 1 & Shell & Emisiones netas cero & \multirow{2}{*}{$\begin{array}{l}\text { Las compañías de petróleo, aún en estos complicados } \\
\text { momentos, no abandonan el camino de la transición a una } \\
\text { energía más limpia y sus objetivos son ambiciosos e } \\
\text { imprecisos para reducir emisiones. Energy (2020) }\end{array}$} \\
\hline 2 & $\mathrm{BP}$ & Más allá del petróleo & \\
\hline 3 & Hershey & \multirow{4}{*}{$\begin{array}{l}\text { Han expresado su } \\
\text { apoyo para acabar } \\
\text { con el niño esclavitud }\end{array}$} & \multirow{4}{*}{$\begin{array}{l}\text { Estudios y películas documentales muestran que el trabajo } \\
\text { infantil todavía constituye la base para la producción barata de } \\
\text { cacao en Occidente África. Christensen et.al. (2020) }\end{array}$} \\
\hline 4 & Mars & & \\
\hline 5 & Nestle & & \\
\hline 6 & Toms & & \\
\hline 7 & Nike & $\begin{array}{l}\text { La igualdad en el } \\
\text { deporte }\end{array}$ & $\begin{array}{l}\text { Nike paga salarios desiguales para sus pr } \\
\text { Christensen et.al. (2020) }\end{array}$ \\
\hline
\end{tabular}

Fuente: Elaborado por el autor con base en los autores citados

De las siete empresas relacionadas en la tabla 1, todas conocidas a nivel mundial, estas han logrado construir en la mente de los consumidores, una imagen que se ha ido desmoronado

\footnotetext{
"Visión de Futuro" Año 19, Volumen $N^{\circ} 26$ Nº 1, Enero - Junio 2022 - Pág 169 - 189

URL de la Revista: http://visiondefuturo.fce.unam.edu.ar/index.php/visiondefuturo/index

URL del Documento: https://visiondefuturo.fce.unam.edu.ar/index.php/visiondefuturo/issue/view/22

ISSN 1668 - 8708 - Versión en Línea

E-mail: $\underline{\text { revistacientifica@fce.unam.edu.ar }}$
} 
por las críticas sobre hipocresía empresarial de que han sido objeto, de la mayoría se han conocido los impactos que han generado en los grupos de interés e incluso algunas han sido objeto de sanciones legales de los países donde operan.

\section{Aspectos de la hipocresía empresarial}

La investigación realizada, nos permite proponer tres aspectos o facetas en las cuales se presenta la hipocresía empresarial, la hipocresía moral; la hipocresía conductual y Como atribuir la hipocresía empresarial, las cuales desarrollaremos a continuación:

\section{Hipocresía moral empresarial}

En primer lugar, analizaremos la propuesta de Hongdan, y Jun. (2017), en la que el daño de la hipocresía moral corporativa no solo se limita al exterior de la empresa, socavando la confianza de los grupos de interés de la empresa, sino también se extiende al interior y no favorece la reputación ni el desarrollo a largo plazo de la empresa, por los daños en la imagen corporativa en la mente de los consumidores, y para Isserow y Klein (2018); y Effron, O'Connor, Leroy y Lucas. (2018), las deviaciones intencionales de las declaraciones pueden ser peores que las involuntaria porque revelan fallas morales, sin embargo, según Farmbrough (2018) las empresas a pesar de sus promesas no actúan siempre según lo prometido, porque para Wagner, et.al. (2019) la empresa está fingiendo ser algo que no es y la empresa intenta parece ser más virtuosa de lo que realmente es, y a menudo afirman Denning, (2020), contradicen sus compromisos con acciones inmorales.

\section{La hipocresía conductual empresarial}

Es la creencia de que las declaraciones realizadas por una empresa se desvían en sus comportamientos, lo cual para Effron et.al. (2018) establece como uno de sus hallazgos más importantes que los grupos de interés pueden presenciar desalineación entre palabras y acciones y que no siempre reaccionan negativamente y a veces reaccionan positivamente. Por su parte Effron et.al. (2018) sugiere que tales acciones ocurren si la desalineación es percibida como baja e interpretada como una moral inmerecida y para Wagner et.al (2019) conducen a percepciones de hipocresía conductual.

\footnotetext{
"Visión de Futuro" Año 19, Volumen No 26 N 1, Enero - Junio 2022 - Pág 169 - 189

URL de la Revista: http://visiondefuturo.fce.unam.edu.ar/index.php/visiondefuturo/index

URL del Documento: https://visiondefuturo.fce.unam.edu.ar/index.php/visiondefuturo/issue/view/22

ISSN 1668 - 8708 - Versión en Línea

E-mail: $\underline{\text { revistacientifica@fce.unam.edu.ar }}$
} 


\section{Como atribuir² la hipocresía empresarial}

La hipocresía es un fenómeno complejo y multifacético, por tanto, tomando como base la teoría de las atribuciones, teniendo en cuenta que gran parte del significado práctico de la teoría de la atribución reside en su utilidad para comprender las preocupaciones motivacionales del mundo real, que se desarrollan todos los días en sus entornos para atribuir la hipocresía empresarial con base en los juicios personales que los grupos de interés hacen en relación con que las empresas son hipócritas por naturaleza, y estas atribuciones, al respecto Wagner et al (2019) afirman que el análisis conduce a distinciones importantes entre hipocresía moral, hipocresía conductual y como atribuir la hipocresía, además muestra que las diferentes facetas de las percepciones de la hipocresía tienen antecedentes distintos y en consecuencia, las prácticas engañosas conducen a percepciones de hipocresía moral, mientras que las prácticas inconsistentes conducen a percepciones de hipocresía conductual, además ambas percepciones conducen a establecer como atribuir la hipocresía.

Por tanto, los estudios sobre hipocresía empresarial deben profundizar el proceso psicológico involucrado en la formación de la percepción de hipocresía corporativa, como el impacto de la atribución en la hipocresía.

\section{Temporalidades de la hipocresía empresarial}

Como se ha mostrado a lo largo de este artículo, la hipocresía empresarial se ha concebido como inconsistencias y estas surgen en múltiples dimensiones, Christensen, et.al., (2020) propone una tipología que involucra dos dimensiones: una orientación y una dirección temporales.

La orientación temporal para Christensen, et.al (2020) se refiere a la capacidad de atención, a corto y largo plazo de participantes al hacer o responder a acusaciones de hipocresía. La dirección temporal se refiere al punto de comparación, pasado o futuro como lo propone Schoeneborn y Vásquez, (2017) y que los participantes se movilizan al discutir tales cargos y Christinsen et.al. (2020) identifica tensiones temporales y actuaciones de hipocresía en ambas dimensiones. (Ver figura1)

\footnotetext{
2 Basada en la teoría de la atribución es una teoría de la psicología social desarrollada fundamentalmente por el psicólogo Fritz Heider en su obra de 1958 The Psychology of Interpersonal Relations (La Psicología de las Relaciones Interpersonales). Heider la definió como un método para evaluar cómo la gente percibe su propio comportamiento y el de los demás

"Visión de Futuro" Año 19, Volumen $N^{\circ} 26$ No 1, Enero - Junio 2022 - Pág 169 - 189

URL de la Revista: http://visiondefuturo.fce.unam.edu.ar/index.php/visiondefuturo/index

URL del Documento: https://visiondefuturo.fce.unam.edu.ar/index.php/visiondefuturo/issue/view/22

ISSN 1668 - 8708 - Versión en Línea

E-mail: revistacientifica@fce.unam.edu.ar
} 


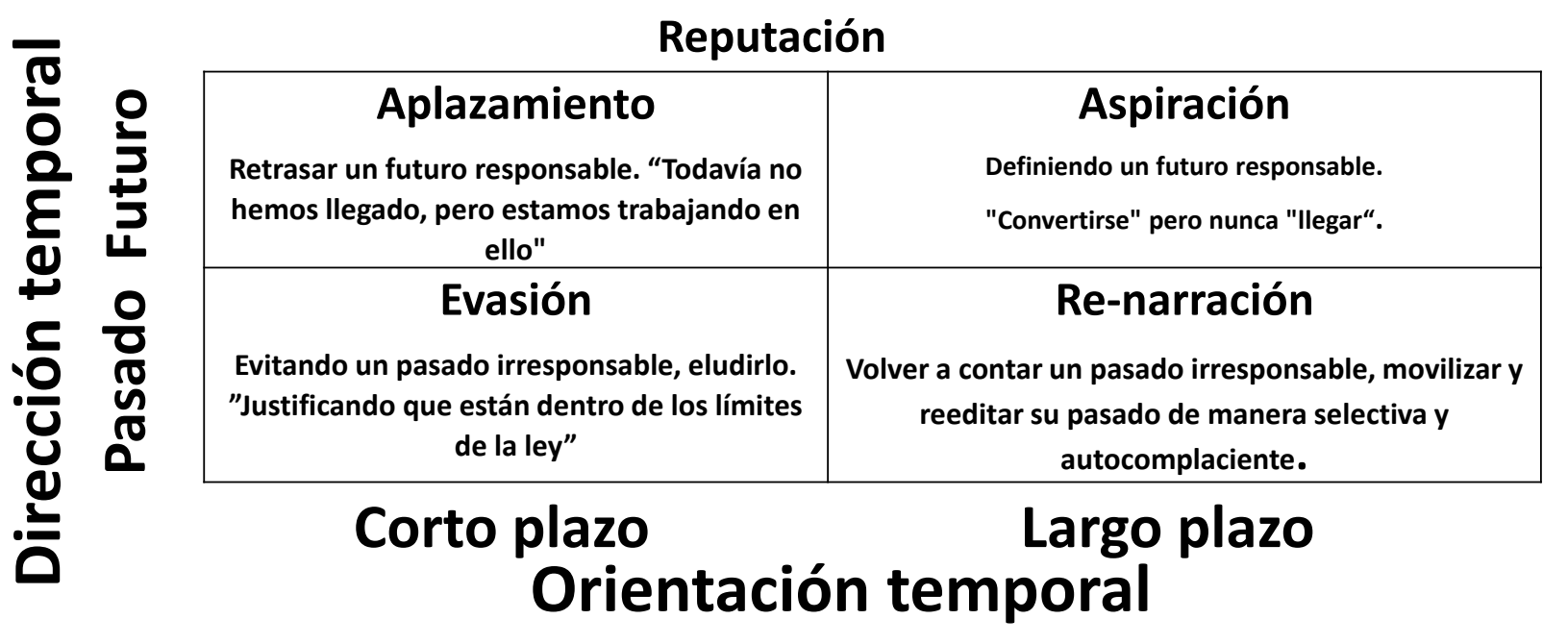

Figura1: Temporalidades de hipocresía en la comunicación

Fuente: Elaborado con base en Christensen, et.al (2020)

\section{Aspiración}

Teniendo en cuenta que las aspiraciones denotan autodescripciones organizacionales, Koep, (2017) propone que las empresas pueden beneficiarse estratégicamente si realizan conversaciones con sus grupos de interés, sobre las aspiraciones, examinando con ellos donde les gustaría que la empresa estuviera y como se puede llegar allí, enfocándose en la propuesta de Morsing (2017) de la interacción dialéctica entre aspiración y desempeño, enfatizando en el potencial que se puede encontrar en las discrepancias entre palabras y acciones.

Por tanto, Christinsen et.al (2020) proponen que es necesario actuar aquí y ahora para evitar que las acciones complejas se orienten hacia un futuro desconocido. Finalmente, Christensen et.al (2020) concluye que el desafío está en combinar un entendimiento de lo que puede hacer la organización, sus aspiraciones, en las circunstancias adecuadas, con una mentalidad abierta, y realizando negociaciones sobre los plazos, que estos sean razonables y aceptable para que los grandes proyectos de interés social, en estos compromisos que implican alta orientación temporal y alta dirección temporal, para no recurrir al aplazamiento de sus aspiraciones.

\section{Aplazamiento}

El aplazamiento se refiere a retrasos, extensiones o suspensiones de las acciones organizaciones hacia un futuro mejor o más responsable, en razón a nueva información o por factores o eventos incontrolables del entorno donde se desenvuelven las organizaciones, como

\footnotetext{
"Visión de Futuro" Año 19, Volumen No 26 No 1, Enero - Junio 2022 - Pág 169 - 189

URL de la Revista: http://visiondefuturo.fce.unam.edu.ar/index.php/visiondefuturo/index

URL del Documento: https://visiondefuturo.fce.unam.edu.ar/index.php/visiondefuturo/issue/view/22

ISSN 1668 - 8708 - Versión en Línea

E-mail: $\underline{\text { revistacientifica@fce.unam.edu.ar }}$
} 
el Covid 19, pandemia que ha modificado las condiciones mundiales de los negocios. El aplazamiento sirve para evadir el pleno conocimiento del límite del tiempo y que la temporalidad consiste en insistir en que siempre se está en un trabajo en progreso, logrando impulsarlo para llegar, además establece que una vez llegado esto es suficiente y que el futuro debe ser un éxtasis que impulsa a llegar, Christensen et.al (2020) y concluyen que el mantenimiento de los ideales y metas a largo plazo son necesarios, al igual que mantener la acción inmediata, porque las prácticas de aplazamiento ilustran la tensión temporal entre el ahora y un futuro ideal.

\section{Evasión}

En relación con la evasión establece Carlos y Lewis, (2018), que se produce cuando una empresa tiene una sólida reputación ambiental y la legitimidad de la certificación de Dow Jones Sustainability Index (DJSI) identifican que estos factores aumentarían la probabilidad de que se detectaran actos hipócritas, lo cual llevó a la empresa a guardar silencio sobre la membresía DJSI.

Finalmente, Christensen et.al (2020) argumenta que la evasión es probable que funcione si se practica de forma silenciosa, o bajo el radar, razón por la cual esta situación incómoda de dejar olvidado el pasado, y participan en la re- narración.

\section{Re-narración}

La re-narración implica reorganizar eventos y símbolo específicos del pasado en una imagen idealizada que se puede utilizar como recurso para orientar y justificar prácticas actuales y metas futuras. Esta estrategia se puede aplicar en una renovación continua de la identidad de la organización, esto implica reabrir el pasado, cerrando el futuro, de esta manera las actualizaciones y revisiones de pasado, son actividades normales en muchas organizaciones, buscando mantener como lo plantea Christensen, et.al (2020) en lugar de rechazar los intentos de reescribir la historia de la organización como hipocresía inaceptable, un enfoque orientado al rescate de la identidad, implica utilizar la tensión entre lo que era la organización y lo que afirma haber sido, logrando sembrar semillas de cambio.

\section{CONCLUSIONES}

En este artículo realizamos las siguientes contribuciones a la investigación de la hipocresía empresarial:

\footnotetext{
"Visión de Futuro" Año 19, Volumen $N^{\circ} 26$ Nº 1, Enero - Junio 2022 - Pág 169 - 189

URL de la Revista: http://visiondefuturo.fce.unam.edu.ar/index.php/visiondefuturo/index

URL del Documento: https://visiondefuturo.fce.unam.edu.ar/index.php/visiondefuturo/issue/view/22

ISSN 1668 - 8708 - Versión en Línea

E-mail: $\underline{\text { revistacientifica@fce.unam.edu.ar }}$
} 
El estudio de la hipocresía inicia desde los años 1700 en adelante pasando por investigación realizada desde la psicología, la filosofía y desde la óptica del direccionamiento estratégico y la gestión empresarial, en la década de los setenta, por tanto, el concepto de hipocresía empresarial específicamente tiene aproximaciones desde 1974 y a partir de este año se realizó una revisión de las definiciones más destacadas.

De la misma forma es importante destacar que, aunque la hipocresía empresarial parece un concepto sencillo a primera vista, esta revisión permite concluir que su comprensión exige un examen riguroso porque lo que se ha realizado es todavía muy limitado,

La investigación proporciona orientaciones a empresarios y académicos en el camino de comprender las implicaciones de la hipocresía empresarial, se identifica en las definiciones analizadas que estas abordan la hipocresía desde una dimensión moral y ética, también desde el comportamiento inapropiado, o con discrepancias en las prácticas como generadoras de comportamientos diferentes o comportamientos del pasado, relacionando la hipocresía empresarial como una inconsistencia o brecha en sus comportamientos diferentes en la realidad, porque no practican lo que predican, como una percepción o juicio de los grupos de interés, porque socavan las actitudes positivas de los grupos de interés, hacia marcas o empresas, revelándose un fenómeno generalizado en todos los contextos y dominios de la investigación sobre el tema, que refleja facetas morales, y que permitieron mostrar que la hipocresía no solo es inestable, sino que juega un papel mucho más complejo en la configuración de las organizaciones contemporáneas, finalmente se llega a una propuesta de definición de hipocresía empresarial.

En los aspectos relacionados con los enfoques desde los cuales se ha estudiado la hipocresía empresarial a saber: desde la responsabilidad social empresarial (RSE), la ética; la reputación, los grupos de interés (stakeholders), y la comunicación se destacan los hallazgos más importantes logrados por los investigadores consultados, posteriormente se realiza una revisión de las consecuencias de la hipocresía empresarial y dieciocho empresas conocidas mundialmente, sus declaraciones y la crítica realizada por hipocresía empresarial, contribuyendo a la literatura sobre hipocresía empresarial explorando las implicaciones de la hipocresía empresarial como efecto de las discrepancias entre lo prometido y lo realizado.

Desde esta perspectiva es importante concluir que el tiempo en el que viven las organizaciones debe percibirse como un ahora eterno, porque el pasado no se cierra fácil y se puede reabrir con nuevos recuerdos que expongan los y hacia los grupos de interés de la empresa.

\footnotetext{
"Visión de Futuro" Año 19, Volumen $N^{\circ} 26$ Nº 1, Enero - Junio 2022 - Pág 169 - 189

URL de la Revista: http://visiondefuturo.fce.unam.edu.ar/index.php/visiondefuturo/index

URL del Documento: https://visiondefuturo.fce.unam.edu.ar/index.php/visiondefuturo/issue/view/22

ISSN 1668 - 8708 - Versión en Línea

E-mail: $\underline{\text { revistacientifica@fce.unam.edu.ar }}$
} 
También se proponen cuatro modos temporales de hipocresía, basados en la perspectiva del tiempo, considerándola en dos dimensiones: una orientación a largo/corto plazo y una dirección pasada/presente, en este marco se presenta la dinámica potencial de la hipocresía y su dependencia del tiempo identificando la aspiración, el aplazamiento, la evasión y la re-narranción, como cuatro formas de hipocresía empresarial.

\section{Implicaciones prácticas}

La principal implicación práctica de este documento es ayudar a los gerentes a comprender la importancia de la coherencia entre el decir y el actuar para evitar que sean percibidos desde la perspectiva de la hipocresía empresarial y afecten la marca, la reputación, la confianza y la credibilidad en la empresa.

\section{REFERENCIAS}

Adams, S. (2015 september 9). The companies with the best CSR reputations in the world, available at: www. forbes.com/sites/susanadams/2015/09/17/the-companies-with-the-best-csrreputations-in-theworld/\#39a8661b4f85 (accedido en junio 23, 2020).

Andersen,S., Høvring ,C.M. (2019). CSR stakeholder dialogue in disguise: Hypocrisy in story performances, Journal of Business Research, https://doi.org/10.1016/j.jbusres.2019.08.030

Argyris, C., y Schon, D. A. (1974). Theory in practice: Increasing professional effectiveness. San Francisco, CA: Jossey-Bass.

Arli, D., Grace, A., Palmer, J. y Pham, C. (2017). Investigating the direct and indirect effects of corporate hypocrisy and perceived corporate reputation on consumers' attitudes toward the company", Journal of Retailing and Consumer Services, Vol. 37, pp. 139-145. https://doi.org/10.1016/j.jretconser.2017.04.002

Arli,D.; van Esch,P.; Northey,G.; Lee,M.; Dimitriu,M.;(2020). Hypocrisy, skepticism, and reputation: the mediating role of corporate social responsibility, Marketing Intelligence \& Planning, Vol. 37 No. 6, 2019 pp. 706-720, DOI 10.1108/MIP-10-2018-0434

Babu,N.; De Roeck,K.; y Raineri, N. (2019). Hypocritical organizations: Implications for employee social responsibility, Journal of Business Research, https://doi.org/10.1016/j.jbusres.2019.07.034

Bakker, F. y Hond, F.; (2017). NGO Activism and CSR," Post-Print hal-01803311, HAL. RePEc:hal:journl:hal-01803311

\footnotetext{
"Visión de Futuro" Año 19, Volumen $N^{\circ} 26$ N 1, Enero - Junio 2022 - Pág 169 - 189

URL de la Revista: http://visiondefuturo.fce.unam.edu.ar/index.php/visiondefuturo/index

URL del Documento: https://visiondefuturo.fce.unam.edu.ar/index.php/visiondefuturo/issue/view/22

ISSN 1668 - 8708 - Versión en Línea

E-mail: $\underline{\text { revistacientifica@fce.unam.edu.ar }}$
} 
Brunsson, N. (1989). The organization of hypocrisy: Talk, decisions and actions in organizations (1. ed.). New York: Wiley.

Carlos, Ch, y Lewis, B. (2018).Strategic Silence: Withholding Certification Status as a Hypocrisy Avoidance Tactic, Administrative Science Quarterly 2018, Vol. 63(1)130-169 DOI: 10.1177/0001839217695089 journals.sagepub.com/home/asq.

Christensen, L.T. ; Morsingb, M. ; y Thyssenc, O. (2020). Timely hypocrisy? Temporalities of hypocrisy in CSR communication, Journal of Business Research 114 (2020) 327-335. https://doi.org/10.1016/j.jbusres.2019.07.020

Denning, S. (2020 January5). Why Stakeholder Capitalism will fail. Forbes. https://www.forbes.com/sites/stevedenning/2020/01/05/why-stakeholder-capitalism will fail/\#1e3c37a785a8. (accedido en junio 26, 2020)

Dickey, L. (1990). Pride, hypocrisy and civility in Mandeville's social and historical theory, Critical Review: A Journal of Politics and Society, 4:3, 387-431, DOI: $10.1080 / 08913819008459612$

Donia, M.B. y Sirsly, C.A.T. (2016). Determinants and consequences of employee attributions of corporate social responsibility as substantive or symbolic", European Management Journal, Vol. 34 No. 3, pp. 232-242. https://doi.org/10.1016/j.emj.2016.02.004

Effron, D. A., O'Connor, K., Leroy, H., y Lucas, B. J. (2018). From inconsistency to hypocrisy: When does "saying one thing but doing another- invite condemnation? Research in Organizational Behavior, Research in Organizational Behavior 38 DOI: 10.1016/j.riob.2018.10.003

Effron, D.A.; O'Connor,K.; y Lucas, L. (2015). Hypocrisy by association: When organizational membership increases condemnation for wrongdoing, Organizational Behavior and Human Decision Processes, http://dx.doi.org/10.1016/j.obhdp.2015.05.001

Energy (2020) https://www.energynews.es/ambiciosos-objetivos-de-shell-para-reduciremisiones/

Etter, M., Ravasi, D., y Colleoni, E. (2019). Social media and the formation of organizational reputation. Academy of Management Review. https://doi.org/10.5465/amr.2014.0280

Farmborough, H. (2018, April 14). H\&M is pushing sustainability hard, but not everyone is convinced. Forbes. https:/www.forbes.com/sites/heatherfarmbrough/2018/04/14/hm-ispushingsustainability-hard-but-not-everyone-is-convinced/\#713700777ebd, (accedido en junio 25, 2020

Goswami, S. (2017). Perceived corporate hypocrisy: scale development in the context of us retail employees. A Dissertation presented to the Faculty of the Graduate School at the University of Missouri-Columbia

\footnotetext{
“Visión de Futuro" Año 19, Volumen No 26 N 1, Enero - Junio 2022 - Pág 169 - 189

URL de la Revista: http://visiondefuturo.fce.unam.edu.ar/index.php/visiondefuturo/index

URL del Documento: https://visiondefuturo.fce.unam.edu.ar/index.php/visiondefuturo/issue/view/22

ISSN 1668 - 8708 - Versión en Línea

E-mail: revistacientifica@fce.unam.edu.ar
} 
Goswami, S., y Ha-Brookshire, J. E. (2016). Exploring US retail employees' experiences of hypocrisy. Organization Management Journal, 13(3), 168-178. https://doi.org/10.1080/15416518.2016.1214064

Greenbaum, R.; Mawritz, M.B. y Piccolo, E.F. (2015). When leaders fail to walk the talk. Supervisor Underminig and perceptions of leader hypocrisy. Journal of Management, 41(3), 929956. https://doi.org/10.1177/0149206312442386

Guèvremont, A., y Grohmann, B. (2018). Does brand authenticity alleviate the effect of brand scandals? Journal of Brand Management, 25(4), 322-336. DOI https://doi.org/10.1057/s41262-017-0084-y

Hafenbrädl,S.; y Waeger, D. (2019). The business case for CSR: A trump card against hypocrisy? Journal of Business Research, https://doi.org/10.1016/j.jbusres.2019.08.043

Hongdan, Z.; y Jun, Z. (2017). Corporate Hypocrisy, Moral Disengagement and Unethical Pro-organizational Behavior: Moderated Mediating Effect, Foreign Economics \& Management Vol. 39, Issue 01, pp. 15 - 28, (2017) DOI:10.16538/j.cnki.fem.2017.01.002

Ioannou, I.; Kassinis, G.; Papagiannakis, G. (2018). All Are Not Saints, Who Go to Church: Corporate Social Responsibility, Perceived Corporate Hypocrisy and the Impact on Customer Satisfaction, Available at SSRN: https://ssrn.com/abstract=3169241 or http://dx.doi.org/10.2139/ssrn.3169241.

Isserow, J.; Klein, C. (2017) Hypocrisy and Moral Authority, Journal of Ethics and Social Philosophy: Vol. 12 No. 2 (2017). Volume XII, Issue 2, 191-222. DOI https://doi.org/10.26556/jesp.v12i2.224

Kerr, S. (1975). On the folly of rewarding a, while hoping for B. Academy of Management Journal, 18(4), 769-783. https://doi.org/10.5465/255378

Kılıçoglu, G.; Kılıçoglu, D.Y.; y Hammersley-Fletcher, L. (2019). Leading Turkish schools: A study of the causes and consequences of organisational hypocrisy. Educational Management Administration y Leadership. DOI: https://doi.org/10.1177/1741143218822778

Koep, L. (2017). Tensions in aspirational CSR communication - A longitudinal investigation of CSR reporting. Sustainability, 9(12), 1-28. https://doi.org/10.3390/su9122202

Leonidou, C. N., y Skarmeas, D. (2017). Gray shades of green: Causes and consequences of green skepticism. Journal of Business Ethics, 144(2), 401-415. DOI

https://doi.org/10.1007/s10551-015-2829-4

\footnotetext{
"Visión de Futuro" Año 19, Volumen N²6 N 1, Enero - Junio 2022 - Pág 169 - 189

URL de la Revista: http://visiondefuturo.fce.unam.edu.ar/index.php/visiondefuturo/index

URL del Documento: https://visiondefuturo.fce.unam.edu.ar/index.php/visiondefuturo/issue/view/22

ISSN 1668 - 8708 - Versión en Línea

E-mail: revistacientifica@fce.unam.edu.ar
} 
Losada-Otálora, M., y Alkire, L. (2019). A transformative approach to corporate social responsibility: an antidote to corporate hypocrisy, The Service Industries Journal, DOI: 10.1080/02642069.2019.1655000

Morsing, M. (2017). CSR communication: What is it? Why is it important? In A. Rashe, Morsing, M. y J. Moon (Eds.). Corporate social responsibility: Strategy, communication, governance (pp. 281-306). Cambridge University Press, UK

Norden-Lowe, R. (1957) Hypocrisy, Detachment and Adaptation, The Psychoanalytic Review, vol.44, No 4, 401-409.October 1957.

Romani, S., Grappi, S., y Bagozzi, R. P. (2016). Corporate socially responsible initiatives and their effects on consumption of green products. J. Bus. Ethics. 135, 253-264. doi: $10.1007 / \mathrm{s} 10551-014-2485-0$

Scheidler, S., Edinger-Schons, L. M., Spanjol, J., y Wieseke, J. (2018). Scrooge posing as Mother Teresa: How hypocritical social responsibility strategies hurt employees and firms. Journal of Business Ethics, 157(2), 339-358, DOI https://doi.org/10.1007/s10551-018-3788-3

Shim, K.; y Yang, S.U. (2016). The effect of bad reputation: The occurrence of crisis, corporate social responsibility, and perceptions of hypocrisy and attitudes toward a company. (2016). Public Relations Review. 42, (1), 68-78. https://doi.org/10.1016/j.pubrev.2015.11.009

Shklar, J. N. (1984). Ordinary vices. Cambridge, Massachusetts and London, England: The Belknap Press of Harvard University Press.

Siano, A., Vollero, A., Conte, F. y Amabile, S. (2017). More than words: expanding the taxonomy of greenwashing after the Volkswagen scandal", Journal of Business Research, Vol. 71, pp. 27-37. https://doi.org/10.1016/j.jbusres.2016.11.002

Sweetin, V. H., Knowles, L. L., Summey, J. H., y McQueen, K. S. (2013). Willingnesstopunish the corporate brand for corporate social irresponsibility. Journal of Business Research, 66(10), 1822-1830. https://doi.org/10.1016/j.jbusres.2013.02.003

Szabados, B. (1979). Hypocrisy, Canadian Journal of Philosophy, 9:2, 195-210 : http://dx.doi.org/10.1080/00455091.1979.10716245

Tedeschi, J. T., Schlenker, B. R., y Bonoma, T. V. (1971). Cognitive dissonance: Private ratiocination or public spectacle? American Psychologist, 26(8), 685-695. https://doi.org/10.1037/h0032110

Wagner,T.; Korschunb,D.; Troebsa,C. (2019). Deconstructing corporate hypocrisy: A delineation of its behavioral, moral, and attributional facets, Journal of Business Research, https://doi.org/10.1016/j.jbusres.2019.07.041

\footnotetext{
"Visión de Futuro" Año 19, Volumen N²6 No 1, Enero - Junio 2022 - Pág 169 - 189

URL de la Revista: http://visiondefuturo.fce.unam.edu.ar/index.php/visiondefuturo/index

URL del Documento: https://visiondefuturo.fce.unam.edu.ar/index.php/visiondefuturo/issue/view/22

ISSN 1668 - 8708 - Versión en Línea

E-mail: $\underline{\text { revistacientifica@fce.unam.edu.ar }}$
} 
Yanga,L;Manikab,D.; Athanasopouloua, A. (2018). Are they sinners or saints? A multi-level investigation of hypocrisy in organizational and employee pro-environmental behavior's, Journal of Business Research, https://doi.org/10.1016/j.jbusres.2019.08.042

Zhao Y, Qin Y, Zhao X, Wang X y Shi, L. (2020). Perception of Corporate Hypocrisy in China: The Roles of Corporate Social Responsibility Implementation and Communication. Front. Psychol. 11:595. doi: 10.3389/fpsyg.2020.00595

Zhigang,W; Lei,Z; y Xintao,L. (2020). Consumer Response to Corporate Hypocrisy From the Perspective of Expectation Confirmation Theory, Front Psychol. 2020; 11: 580114. Published online 2020 Nov 16. doi: 10.3389/fpsyg.2020.580114

\section{RESUMEN BIOGRÁFICO}

\section{Manuel Alfonso Garzón Castrillón}

Pósdoutorado em Universidade de São Paulo, Brasil; PhD MSc. Profesional en Administración de Empresas, Actualmente Director del grupo de Investigación FIDEE, Email: manuelalfonsogarzon@fidee.org, Intereses actuales: Capacidades dinámicas; Gestión de la diversidad, Gestión de la felicidad; Gestión del conocimiento. ORCID ID http://orcid.org/0000- 0001-9009-3324.

\footnotetext{
"Visión de Futuro" Año 19, Volumen No 26 N 1, Enero - Junio 2022 - Pág 169 - 189

URL de la Revista: http://visiondefuturo.fce.unam.edu.ar/index.php/visiondefuturo/index

URL del Documento: https://visiondefuturo.fce.unam.edu.ar/index.php/visiondefuturo/issue/view/22

ISSN 1668 - 8708 - Versión en Línea

E-mail: $\underline{\text { revistacientifica@fce.unam.edu.ar }}$
} 